\title{
Upaya Peningkatan Kesehatan Edukasi Kesiapan Warga dalam Menghadapi Bencana Fase Impact di Desa Wonorejo Karanganyar
}

\author{
Ika Subekti Wulandari ${ }^{1 *}$, Maria Wisnu Kanita ${ }^{2}$ \\ ${ }^{1,2}$ Universitas Kusuma Husada Surakarta \\ *Email: ika@ukh.ac.id
}

\begin{abstract}
Background: Indonesia is included in the list of countries most at risk of disaster. So that disaster preparedness is needed which is an effort to prevent the onset of crisis due to disaster which is focused on developing plans to deal with disasters. The problem that arises is that there are still many Indonesian citizens who do not know and understand what a disaster is, how to anticipate and overcome a disaster. The purpose of this community service is to increase community preparedness in the face of the impact phase of disaster in the village of Karanganyar Wonorejo. Methods: The design of this study was a quasiexperiment with a pre-post without control group design involving 29 respondents. Result: The results of education on the readiness of residents in facing the impact phase of the disaster proved to significantly increase knowledge with a p-value of 0.006. Conclusion: Increasing the readiness of citizens in facing disasters in the impact phase can be done by providing massive education and information to the community
\end{abstract}

Keywords: Citizens, Disasters, Education, Impact Phase

\section{PENDAHULUAN}

Kesiapan warga masyarakat dalam menghadapi bencana harus dikelola secara maksimal dikarenakan bencana dapat datang secara tiba-tiba. Indonesia mendapat julukan ring of fire atau jalur lingkaran gempa karena secara geografis wilayah Indonesia berbatasan dengan tiga lempengan besar dunia yaitu : lempengan IndoAustralia, Pasifik dan Eurasia sepanjang 1.200 Km serta Indonesia juga terletak pada tiga sistem pegunungan (Alpine Sunda, Circum Australia dan Circum Pasifik). Indonesia merupakan negara kepulauan yang terdiri dari 2/3 lautan, 500 gunung berapi dengan 128 diantaranya statusnya masih aktif, dan 5.000 sungai yang melewati wilayah padat penduduk. Beberapa kondisi tersebut memiliki potensi untuk memicu terjadinya berbagai bencana alam (Paidi 2012).

Menurut Badan Pencegahan Bencana PBB atau United Nations International Strategy for Disaster Reduction Indonesia termasuk negara yang memiliki resiko bencana tertinggi. Berdasarkan kemampuan masyarakat dan negara dalam menghadapi bencana Indonesia masuk urutan daftar ke sembilan di Negara Asia bersama Bangladesh, China, India dan Myanmar. Semua jenis bencana hampir pernah terjadi di Indonesia, oleh karena itu Indonesia dikenal sebagai supermarketnya bencana (Ambarika 2016).

Tingginya angka kejadian bencana di Indonesia menuntut semakin baiknya manajemen resiko bencana sebagai upaya penanggulangan bencana yang optimal dan sistematis. Fenomena yang ada di Indonesia adalah masih rendahnya pengetahuan dan kesiapan masyarakat dalam merespon bencana tentang bagaiamana mengantisipasi dampak bencana, bagaimana bertahan hidup dalam kondisi bencana dan bagaimana evakuasi yang tepat. Beberapa hal tersebut jika dipersiapkan dengan 
baik akan mampu meminimalisir resiko dampak yang ditimbulkan dari bencana yang terjadi (Paidi 2012).

Kesiapan menghadapi bencana atau disaster preparedness adalah usaha untuk mencegah munculnya dampak krisis yang ditimbulkan bencana dengan berkonsentrasi pada pengoptimalan upaya-upaya menghadapi bencana. Kesiapsiagaan terhadap bencana memiliki tujuan untuk meminimalisir trauma atau luka pada korban, mengurangi jumlah korban, menghindari munculnya masalah kesehatan post bencana dan mempermudah usaha tanggap darurat dan rehabilitasi yang tepat (Kemenkes RI 2007). Aspek-aspek dalam kesiap-siagaan bencana mencakup tingkat pengetahuan individu, masyarakat dan tingkat nasional baik di lingkup pemerintah maupun swasta mengenai mitigasi dan hazard yang dimiliki. Aspek penting lain yang merupakan bentuk kesiapan bencana adalah pendidikan mengenai bencana, respon terhadap dampak bencana serta pengembangan erly warning system sebagai upaya kesiapan menghadapi bencana (Juanita, Suratmi, and Maghfiroh 2018). Aspek-aspek tersebut merupakan dasar pengetahuan yang harus disosialisaikan kepada masyarakat di tatanan komunitas.

Desa Wonorejo berada di wilayah Kabupaten Karanganyar Jawa Tengah, berbatasan dengan daerah Surakarta dan Kabupaten Sragen. Menurut data Badan Penanggulangan Bencana Daerah (BPPD) Kabupaten Karanganyar, Kecamatan Gondangrejo termasuk daerah yang rawan bencana diantaranya banjir, tanah longsor dan angin puting beliung. Selain itu daerah tersebut juga rawan bencana gempa bumi dan kebakaran.Berdasarkan observasi yang dilakukan di lapangan, selama ini belum ada penyuluhan yang diberikan terkait kesiapsiagaan masyarakat dalam bencana fase impact. Oleh karena itu kami tertarik untuk memberikan edukasi tentang kesiapan masyarakat dalam menghadapi bencana fase impact di Desa Wonorejo Karanganyar.

\section{TINJAUAN PUSTAKA}

Menurut Asian Disaster Reduction Center (ARDC), bencana adalah sebuah gangguan yang berdampak kepada masyarakat baik secara material dan non material serta menimbulkan kerugian yang meluas dan melebihi kemampuan masyarakat serta sumber daya yang ada untuk mengatasinya (Ambarika 2016). Upaya dalam merespon bencana dilakukan dengan manajemen penanggulangan bencana yang terstruktur.

Menurut Undang-Undang Nomor 24 Tahun 2007, sistem penanggulangan bencana dibagi menjadi 3 fase yatiu: pra bencana, bencana dan Post bencana. Pada fase pra bencana pencegahan lebih dikonsentrasikan pada kesiapsiagaan level menengah. Upaya penanggulangan bencana pada tahap ini dapat dilakukan melalui pencegahan agar tidak terjadi bencana, mitigasi untuk mengurangi resiko terjadinya bencana baik dengan pembangunan secara fisik maupaun peningkatan kemampuan dalam menghadapi bencana serta kesiapsiagaan untuk mencegah bencana melalui pengorganisasian dan langkah sistem penanggulanagn bencana yang tepat. Pada fase bencana yaitu saat kejadian krisis tanggap darurat melalui peringatan dini yang bersifat segera, tegas, resmi dan menjangkau seluruh masyarakat. Selain peringatan dini juga bisa dilakukan upaya tanggap darurat yang bertujuan menanggulangi akibat 
yang ditimbulkan berupa usaha dalam penyelamatan korban dan harta benda, sistem evakuasi dan pengungsian serta pemberian bantuan logistik untuk bertahan hidup. Pada fase post bencana berkonsentrasi untuk pemulihan dengan memfungsikan kembali sarana dan prasarana, rehabilitasi untuk membantu masyarakat memperbaiki rumah dan tempat tinggal, fasilitas umum dan ekonomi serta rekontruksi guna mengembalikan kehidupan masyarakat pada kondisi lebih baik atau sama dengan kondisi sebelumnya(Kemenkes RI 2007).

Kesiapan bencana (disaster preparedness) adalah kesiapan yang mencakup zona personal, rumah tangga dan komunitas masyarakat dalam menghadapi bencana alam, mengembangkan dan menerapkan perencanaan emergency, menyiapkan perlengkapan siaga bencana di rumah, mendapatkan pendidikan bencana, menjadi relawan pada kondisi bencana dan menjadi donor darah untuk para korban bencana (Juanita et al. 2018).

Kesiapsiagaan bencana pada tingkat personal dapat diukur melalui pengetahuan bencana, perencanaan emergency individu dan akses sumber mobilisasi (Adhiwijaya and Hanaruddin 2019). Aspek pengetahuan meliputi pengertian, teknik evakuasi diri, sarana evakuasi dan sumber akses informasi tentang resiko bencana merupakan aspek penting dalam kesiapan bencana. Perencanaan emergency personal meliputi persiapan keadaan emergency, menerapkan tindakan untuk evakuasi diri dan orang lain saat bencana, menyiapkan peralatan untuk kondisi darurat dan memiliki keterampilan dalam hal keamanan. Persiapan akses sumber mobilisasi meliputi persiapan terhadap periode rekontruksi atau rehabilitasi dan persiapan untuk mencari bantuan dari orang lain selama bencana.

Pelatihan atau training adalah salah satu tehnik yang memberikan pengalaman dan pengetahuan kepada masyarakat sehingga bisa merupah perilaku. Kesuksesan panggulangan bencana sangat ditentukan oleh sistem pelatihan yang diberikan kepada masyarakat. Pelatihan yang disesuaikan dengan kurikulum dan berlangsung secara berkelanjutan akan berdampak pada kesiapsiagaan warga ketika merespon bencana yang terjadi. Selanjutnya kesiapan juga dapat ditingkatkan melalui beberapa simulasi bencana dengan melibatkan masyarakat secara langsung pada kondisi yang disetting seperti realita bencana sesungguhnya (Putra, Kep, and Petpichetchian 2011).

\section{METODE}

Jenis penelitian ini adalah kuantitatif dengan pendekatan quasi eksperimental design dengan rancangan pre test-post test without control group design (Sugiyono, 2014). Tempat pelaksanaan kegiatan di Perumahan Wonochrisan Desa Wonorejo Karangayar. Pendidikan Kesehatan dilakukan dengan media audiovisual yang diberikan 1 kali selama 60 menit melaui whatsapp group pada tanggal 6 Juli 2020. Populasi dalam penelitian ini adalah seluruh ibu anggota paguyuban perumahan sejumlah 30 orang. Teknik pengambilan sampel dengan Incidental Sampling yang melibatkan 29 responden. Tingkat pengetahuan diukur dengan menggunakan kuisioner berisi 10 pertanyaan terkait upaya penyelamatan diri saat bencanna, komunikasi dalam bencana dan konsep survival atau bertahan hidup dalam kondisi 
bencana. Responden diberikan edukasi tentang kesiapan menghadapi bencana gempa bumi, banjir, gunung meletus dan kebakaran kemudian diukur perbedaan pengetahuan pre dan post mengikuti edukasi. Data perbedaan pengetahuan pre dan post edukasi diolah menggunakan uji wilcoxon.

\section{HASIL}

Berdasarkan hasil perhitungan nilai pre test dan post tes edukasi kesiapan warga dalam menghadapi bencana fase impact. Didapatkan data sebagai berikut:

Tabel 1. Distribusi Tingkat Pengetahuan Pre dan Post Test Edukasi Kesiapan Warga dalam Menghadapi Bencana Fase Impact (n: 29)

\begin{tabular}{lcccc}
\hline Pengetahuan & Pre & \% & Post & \% \\
\hline Baik & 20 & 69 & 25 & 86 \\
\hline Cukup & 5 & 17 & 4 & 14 \\
\hline Kurang & 4 & 14 & 0 & 0 \\
\hline Total & 29 & 100 & 29 & 100
\end{tabular}

Berdasarkan tabel 1. Didapatkan data bahwa terdapat kenaikan tingkat pengetahuan dari 20 responden dengan kategori baik, setelah dilakukan edukasi meningkat menjadi 25 responden. Dari 5 responden kategori cukup setelah dilakukan edukasi menjadi 4 responden dan tidak ada responden yang memilki kategori pengetahuan kurang setelah dilakukan edukasi.

Berdasarkan hasil analisa perbedaan pengetahuan pre dan post tes edukasi kesiapan warga dalam menghadapi bencana fase impact dengan menggunakan wilcoxon didapatkan hasil bahwa terdapat perbedaan tingkat pengetahuan warga dalam mengahadapi bencana fase impact yang signifikan antara sebelum dan sesudah mengikuti edukasi dibuktikan dengan nilai p-value 0,006 .

\section{PEMBAHASAN}

Peningkatan level pengetahuan berbading lurus dengan aksesabilitas informasi dan sistem yang melingkupi manajemen disaster. Lembaga Ilmu Pengetahuan Indonesia (LIPI) bekerja sama dengan United Nations for Education/International Strategy for Disaster Reduction (UNESCI/ISDR) mengembangkan framework kesiapsiagaan komunitas pada tahun 2006. Studi dilakukan dengan beberapa tehnik yaitu brainstorming, focus group discussion, clue card dan desk review. Dari studi tersebut didapatkan 5 faktor yang berhubungan dengan kesiapsiagaan yaitu:1) Pengetahuan yang berhubungan dengan fenomena alam dan kesiagaan 2) Kebijakan peraturan dan panduan, 3) Rencana kondisi emergency dan bencana, 4) Early Warning System, 5) Mobilisasi sumber daya. Kelima parameter tersebut merupakan parameter standar untuk mengukur kesiapsiagaan komunitas. Tingkat kesiapsiagaan diketahui dari nilai indeks gabungan kelima indikator tersebut. Individu dan rumah tangga merupakan aspek terpenting, subjek dan objek dari kesiap--siagaan karena berhubungan secara langsung terhadap risiko bencana (Hidayati 2008). 
Pada kondisi bencana, sebagian anggota masyarakat merasa panik dan psikologis tidak stabil, sehingga inisiatif untuk menyelamatkan dan membantu korban sangat minim. Pada kasus yang lain masyarakat tidak membantu yang lain karena tidak mengetahui apa yang haris dilakukan, selain itu ada juga yang berupaya membantu korban tetapi malah menimbulkan masalah baru karena ketidaktahuannya. Contohnya ketika melakukan evakuasi pada korban patah tulang atau trauma cervikal, jika tidak dilakukan dengan tepat akan memperparah kondisi korban. Oleh karena itu edukasi tentang tehnik evakuasi dan pertolongan pertama yang tepat sangat penting diberikan kepada masyarakat. Peran serta masyarakat sangat penting dalam penanggulangan bencana. Dalam lingkup yang kecil adalah kesiapsiagaan diri dan keluarga masing-masing sedangkan pada lingkup yang besar adalah kesiapsiagaan dalam tatanan komunitas (Hidayati 2008).

Sebagian besar masyarakat masih belum siap dalam menghadapi bencana, padahal di Indonesia berada di daerah rawan bencana alam. Selama ini manajemen bencana sebagian besar masih berfokus pada fase pasca bencana, sehingga pengurangan resiko bencana kurang maksimal. Sehingga pergeseran paradigma manajemen bencana penting dilakukan. Paradigma manajemen bencana harus dirubah ke pengelolaan kesiapsiagaan masyarakat dalam mengurangi resiko bencana. Peningkatan pengetahuan dan keterampilan dalam upaya pengurangan resiko bencana merupakan hal yang harus diperhatikan untuk warga masyarakat yang tinggal di daerah rawan bencana. Saat ini upaya peningkatan kesiapsiagaan mulai dilakukan oleh berbagai pihak, akan tetapi hasil studi menunjukkan bahwa pemerintah, komunitas sekolah dan rumah tangga masih memiliki kesiapsiagaan yang rendah dalam menghadapi bencana. Hal ini menunjukkan bahwa kesiapan masyarakat masih perlu terus ditingkatkan agar resiko dampak bencana dapat diminimalisir (Susilowati, 2018).

Menurut penelitian Kapucu (2008) tingkat pendidikan seseorang dapat mempengaruhi perilaku yang merefleksikan kesiapsiagaan bencana seseorang. Secara teori semakin tinggi pendidikan individu maka akan semakin mudah dalam menyerap informasi. Untuk membentuk level kesiapan bencana yang tinggi dibutuhkan program pendidikan dan penyuluhan yang masif sehingga masyarakat dapat melakukan tindakan yang tepat dan menurunkan korban jiwa terutama saat fase kritis yaitu 72 jam pertama post bencana.

Duong (2009) menjelaskan bahwa masih miminmya pakar bencana dan kurikulum bencana baik klinik maupun komunitas sesuai standar pendidikan merupakan beberapa faktor yang menghambat akses pendidikan bencana. Data tersebut juga didukung penelitian (McAlister 2011) bahwa kesiapan seseorang maupun masyarakat dalam menghadapi bencana dipengaruhi oleh frekuensi terpaparnya informasi mengenai bencana. Sedangkan kemauan seseorang untuk mengumpulkan informasi sangat dipengaruhi oleh matovasi internal seseorang. Menurut Putra, Kep dan Petpichetchian (2011) Perawat komunitas memiliki peran yang penting dalam meberikan penyuluhan, pelatihan dan bebagi pengalaman tentang bagaiman berespon terhadap bencana baik pada fase mitigasi, preparedness, impact maupun rehabilitasi. Hal tersebut dikarenakan perawat komunitas memiliki 
akses yang mudah kepada masyarakat sehingga sudah terbangun sikap bina hubungan saling percaya yang baik.

Minimnya sumber daya manusia dalam menyebarkan informasi terkait kesiapan masyarakat terhadap bencana bisa ditopang dengan kemajuan teknologi saat ini. Metode pelatihan bencana dengan virtual reality dapat menjadi salah satu solusi untuk masalah ini. Metode Virtual reality Simmulation (VRS) mampu meberikan gambaran dan suasana yang menyerupai kondisi nyata, sehingga sikap dan motivasi masyarakat saat mengahadapi bencana dapat terfasilitasi secara maksimal. Metode VRS juga lebih efektif dan efisien dibandingkan dengan metode konvensional (Farra and Miller 2012).

Kesiapsiagaan seseorang akan semakin meningkat seiring dengan semakin seringnya distimulasi melalui simulasi dan drill. Pemaparan informasi mengenai halhal yang perlu dilakukan dan dihindari selama fase impact akan memudahkan masyarakat dalam mengambil keputusan saat terjadi bencana. Seringnya melakukan simulasi dan juga pelatihan adalah salah satu cara untuk meningkatkan kesiapsiagaan masyarakat dalam fase preparedness (McAlister 2011). Fase preparednes yang dikelola dengan baik dan disiapkan secara optimal baik dari segi kebijakan, sistem manajemen bencana, sumber daya serta pengetahuan dan kesiapan masyarakat akan memperkecil hazard dan dampak pasca bencana yang terjadi. Begitu sebaliknya jika fase preparednes tidak disiapkan secara maksimal, maka hazard dan dampak pasca bencana yang terjadi akan semakin berat (Schlegelmilch, Petkova, and Redlener 2015).

Penelitian Kapucu (2008) menyebutkan bahwa level kesiapsiagaan masyarakat cenderung meningkat saat fase impact karena mereka memiliki tingkat kewaspadaan yang lebih tinggi pada fase tersebut. Seseorang akan belajar dan beradaptasi selama berada dalam situasi bencana sehingga masyarakat mampu merespon ancaman bencana secara reaktif. Pada level individu, pengalaman dalam merespon bencana akan membawa dampak positif terhadap motivasi internal seseorang dalam menghadapi bencana selanjutnya.

Menurut (Marlyono and Nandi 2018) yang melakukan studi tentang level kesiapan masyarakat saat mengahadapi bencana di Jawa barat menemukan bahwa terdapat perbedaan kesiapan masyarakat yang signifikan anatar daerah Garut, Tasikmalaya dan Pangandaran. Hal ini disebabkan karena adanya perbedaan sarana pendukung seperti alarm peringatan, spanduk atau papan informasi tentang kebencanaan, serta instruksi rute evakuasi. Faktor lain adalah minimnya informasi yang diberikan terkait persiapan apa yang harus dilakukan saat menghadapi bencana.

Sistem manajemen bencana yang baik akan tercapai ketika semua elemen berkolaborasi sesuai dengan bagian atau tugas masing-masing. Kolaborasi antara bagian kesehatan masyarakat dan bagian emergency respon akan sama-sama menghasilkan kinerja yang bermanfaat pada masing-masing fase bencana baik mitigasi, preparedness, respon dan rehabilitasi (Magnani 2018). 


\section{KESIMPULAN DAN SARAN}

\subsection{Kesimpulan}

Berdasarkan hasil yang diperoleh dapat ditarik kesimpulan bahwa salah satu cara untuk meningkatkan kesiapan warga dalam menghadapi bencana fase impact adalah dengan memberikan edukasi dan informasi mengenai aspek-aspek yang harus diketahui warga dalam bencana.

\subsection{Saran}

Saran bagi kader kesehatan dapat melaksanakan penyuluhan dalam kaitannya kesiapan warga dalam menghadapi bencana fase impact (bencana gempa bumi, banjir, gunung meletus dan kebakaran) dan masyarakat diharapkan masyarakat mampu menyiapkan diri dan melakukan tindakan evakuasi dan persiapan emergency jika sewaktu-waktu terjadi bencana.

\section{UCAPAN TERIMA KASIH}

Ucapan terima kasih kami haturkan kepada pihak-pihak yang telah membantu terlaksananya kegiatan pengabdian masyarakat ini yaitu Universitas Kusuma Husada Surakarta, Pro Emergency dan Paguyuban Perum Wonochrisan Regency Desa Wonorejo.

\section{DAFTAR RUJUKAN}

Adhiwijaya, Ardian, and Dewi Yuliani Hanaruddin. (2019). "Kesiapan Tanggap Bencana Mahasiswa Keperawatan UIN Alauddin Makassar.” 08(2):117-22.

Ambarika, Rahmania. (2016). "Efektivitas Edukasi Dan Simulasi Manajemen Bencana Terhadap Kesiapsiagaanan Menjadi Relawan Bencana." Jurnal Kesehatan Mesencephalon 2(4):245-50.

Duong, Karen. (2009). "Disaster Education and Training of Emergency Nurses in South Australia." Australasian Emergency Nursing Journal 12(3):86-92.

Farra, Sharon L., and Elaine T. Miller. (2012). "Integrative Review: Virtual Disaster Training." Journal of Nursing Education and Practice 3(3):93-101.

Hidayati, Deny. (2008). "Kesiapsiagaan Masyarakat: Paradigma Baru Pengelolaan Bencana Alam (Community Preparedness: New Paradigm in Natural Disaster Management).” Jurnal Kependudukan Indonesia 3(1):69-84.

Juanita, Farida, Suratmi Suratmi, and Isni Lailatul Maghfiroh. (2018). "The Effectiveness of Basic Training on Disaster Management Pilot Program for Disaster Preparedness in Community." Indonesian Nursing Journal of Education and Clinic (Injec) 2(2):126.

Kapucu, Naim. (2008). "Culture of Preparedness: Household Disaster Preparedness." Disaster Prevention and Management: An International Journal 17(4):526-35. 
Kemenkes RI. (2007). “KMK No. 145 Tentang Pedoman Penanggulangan Bencana Bidang Kesehatan."

Magnani. (2018). “乳鼠心肌提取 HHS Public Access.” Physiology \& Behavior 176(1):139-48.

Marlyono, S. G., and N. Nandi. (2018). "The Preparedness Level of Community in Facing Disaster in West Java Province." IOP Conference Series: Earth and Environmental Science 145(1).

McAlister, Vivian.(2011). "Drills and Exercises: The Way to Disaster Preparedness." Canadian Journal of Surgery 54(1):7-8.

Mu, Ari. (2019). 済無No Title No Title. Vol. 53.

Paidi. (2012). "Pengelolaan Manajemen Risiko Bencana Alam Di Indonesia.” Widya (83):37.

Putra, Ardia, S. Kep, and Wongchan Petpichetchian. (2011). "Review Public Health Nurses' Roles and Competencies in Disaster Management." Nurse Media: Journal of Nursing 1(1):1-14.

Schlegelmilch, Jeff, Elisaveta Petkova, and Irwin Redlener. (2015). "Disaster Prepared: How Federal Funding in the USA Supports Health System and Public Health Readiness." Journal of Business Continuity \& Emergency Planning 9(2):112-18. 